\title{
Naturally occurring Toll-like receptor 11 (TLR11) and Toll-like receptor 12 (TLR12) polymorphisms are not associated with Toxoplasma gondii infection in wild wood mice
}

\author{
Morger, Jennifer ; Bajnok, Jaroslav ; Boyce, Kellyanne ; Craig, Philip S ; Rogan, Michel T ; Lun, \\ Zhao-Rong ; Hide, Geoff ; Tschirren, Barbara
}

\begin{abstract}
Toxoplasma gondii is a highly successful parasite with a worldwide prevalence. Small rodents are the main intermediate hosts, and there is growing evidence that $\mathrm{T}$. gondii modifies their behaviour. Chronically infected rodents show impaired learning capacity, enhanced activity, and, most importantly, a reduction of the innate fear towards cat odour. This modification of host behaviour ensures a successful transmission of T. gondii from rodents to felids, the definitive hosts of the parasite. Given the negative fitness consequences of this behavioural manipulation, as well as an increased mortality during the acute phase of infection, we expect rodents to evolve potent resistance mechanisms that prevent or control infection. Indeed, studies in laboratory mice have identified candidate genes for T. gondii resistance. Of particular importance appear to be the innate immune receptors Toll-like receptor 11 (TLR11) and Toll-like receptor 12 (TLR12), which recognise T. gondii profilin and initiate immune responses against the parasite. Here we analyse the genetic diversity of TLR11 and TLR12 in a natural population of wood mice (Apodemus sylvaticus), and test for associations between TLR11 and TLR12 polymorphisms and T. gondii infection, as well as for epistatic interactions between TLR11 and TLR12 on infection status. We found that both TLR11 and TLR12 were polymorphic in wood mice, with four and nine amino acid haplotypes, respectively. However, we found no evidence that TLR11 or TLR12 genotypes or haplotypes were significantly associated with Toxoplasma infection. Despite the importance of TLR11 and TLR12 in $\mathrm{T}$. gondii recognition and immune defence initiation, naturally occurring polymorphisms at TLR11 and TLR12 thus appear to play a minor role in mediating qualitative resistance to $\mathrm{T}$. gondii in natural host populations of A. sylvaticus. This highlights the importance of assessing the role of candidate genes for parasite resistance identified in a laboratory setting in an ecologically meaningful context to quantify their role in mediating host-parasite interactions in the wild.
\end{abstract}

DOI: https://doi.org/10.1016/j.meegid.2014.05.032

Posted at the Zurich Open Repository and Archive, University of Zurich

ZORA URL: https://doi.org/10.5167/uzh-98299

Journal Article

Accepted Version

Originally published at:

Morger, Jennifer; Bajnok, Jaroslav; Boyce, Kellyanne; Craig, Philip S; Rogan, Michel T; Lun, Zhao-Rong; Hide, Geoff; Tschirren, Barbara (2014). Naturally occurring Toll-like receptor 11 (TLR11) and Toll-like receptor 12 (TLR12) polymorphisms are not associated with Toxoplasma gondii infection in wild wood mice. Infection, Genetics and Evolution, 26:180-184. 
DOI: https://doi.org/10.1016/j.meegid.2014.05.032 
Naturally occurring Toll-like receptor 11 (TLR11) and Toll-like receptor 12

(TLR12) polymorphisms are not associated with Toxoplasma gondii infection in wild wood mice

Jennifer Morger ${ }^{\mathrm{a}}$, Jaroslav Bajnok ${ }^{\mathrm{b}}$, Kellyanne Boyce ${ }^{\mathrm{b}}$, Philip S. Craig ${ }^{\mathrm{b}}$, Michael T. Rogan $^{\mathrm{b}}$, Zhao-Rong Lun ${ }^{\mathrm{b}, \mathrm{c}}$, Geoff Hide ${ }^{\mathrm{b}}$ \& Barbara Tschirren ${ }^{\mathrm{a}^{*}}$

${ }^{a}$ Institute of Evolutionary Biology and Environmental Studies, University of Zurich, Winterthurerstrasse 190, CH-8057 Zurich, Switzerland

${ }^{b}$ Ecosystems and Environment Research Centre and Biomedical Research Centre, School of Environment and Life Sciences, University of Salford, Salford, M5 4WT, UK

${ }^{\mathrm{c}}$ Center for Parasitic Organisms, State Key Laboratory of Biocontrol, School of Life Sciences and Key Laboratory of Tropical Disease Control of the Ministry of Education, Zhongshan School of Medicine, Sun Yat-Sen University, Guangzhou 510275, China

${ }^{*}$ Corresponding author: Barbara Tschirren, Institute of Evolutionary Biology and Environmental Studies, University of Zurich, Winterthurerstrasse 190, CH-8057 Zurich, Switzerland, email: barbara.tschirren@ieu.uzh.ch, phone: +41446354777

Running headline: TLR variation and Toxoplasma gondii infection 
Abstract

Toxoplasma gondii is a highly successful parasite with a worldwide prevalence. Small rodents are the main intermediate hosts, and there is growing evidence that $T$. gondii modifies their behavior. Chronically infected rodents show impaired learning capacity, enhanced activity, and, most importantly, a reduction of the innate fear towards cat odour. This modification of host behavior ensures a successful transmission of $T$. gondii from rodents to felids, the definitive hosts of the parasite. Given the negative fitness consequences of this behavioral manipulation, as well as an increased mortality during the acute phase of infection, we expect rodents to evolve potent resistance mechanisms that prevent or control infection. Indeed, studies in laboratory mice have identified candidate genes for $T$. gondii resistance. Of particular importance appear to be the innate immune receptors Toll-like receptor 11 (TLR11) and Toll-like receptor 12 (TLR12), which recognize $T$. gondii profilin and initiate immune responses against the parasite.

Here we analyse the genetic diversity of $T L R 11$ and $T L R 12$ in a natural population of wood mice (Apodemus sylvaticus), and test for associations between TLR11 and TLR12 polymorphisms and T. gondii infection, as well as for epistatic interactions between TLR11 and TLR12 on infection status. We found that both TLR11 and TLR12 were polymorphic in wood mice, with four and nine amino acid haplotypes, respectively. However, we found no evidence that TLR11 or TLR12 genotypes or haplotypes were significantly associated with Toxoplasma infection. Despite the importance of TLR11 and TLR12 in T. gondii recognition and immune defence initiation, naturally occurring polymorphisms at TLR11 and TLR12 thus appear to play a minor role in mediating qualitative resistance to $T$. gondii in natural host populations of $A$. sylvaticus. This highlights the importance of assessing the role of candidate genes for parasite resistance identified in a laboratory setting in an 
ecologically meaningful context to quantify their role in mediating host-parasite interactions in the wild.

Keywords: Toxoplasma gondii, Toll-like receptors, immunogenetics, parasite resistance, Apodemus sylvaticus, zoonotic disease 


\section{Introduction}

Individuals differ substantially in their susceptibility to parasites and pathogens, and this variation has at least partly a heritable basis (Kaslow et al., 2008). Genetic diversity in host resistance can be maintained by several non-mutually exclusive mechanisms, including negative frequency-dependent selection, overdominance, or temporal and spatial variation in the composition of the parasite community (Apanius et al., 1997; Hedrick, 2002; Woolhouse et al., 2002). Due to their intimate interaction with the parasite, genes involved in parasite recognition, rather than immune signalling or effector genes, are predicted to be main targets of parasite-mediated directional selection (Tiffin and Moeller, 2006; Sackton et al., 2007; but see Fumagalli et al., 2009; Turner et al., 2012).

Biomedical research has identified candidate genes involved in host defence against a large number of disease causing agents (Hill, 2001). A common approach is to use knockout mice, in which the target gene has been made inoperative, to demonstrate an increased susceptibility to experimental infections (Li et al., 1999; Alexopoulou et al., 2002). Whereas such an approach can provide important insights into parasite infection and host defence pathways, it is agnostic about the level of naturally occurring polymorphisms (laboratory mice are usually highly inbred), or the role of the identified gene in coevolutionary processes in natural populations. Indeed, parasite-mediated selection can only act if there is variation in host defence traits.

Thus, it remains largely unclear if candidate genes for parasite resistance identified in a laboratory setting mediate variation in host resistance under ecologically meaningful conditions, especially in non-human vertebrates.

Also, there is accumulating evidence that environmental factors play a crucial role in shaping immune system functioning, and thus the way hosts interact with their parasites (Abolins et al., 2011; Boysen et al., 2011). Therefore, we may gain 
important insights into the evolution and function of the vertebrate immune system by studying patterns of infection in natural host-parasite systems (Pedersen and Babayan, 2011; Maizels and Nussey, 2013; Turner and Paterson, 2013). This could prove to be particularly fruitful for our understanding of defence strategies against zoonotic diseases, given the long co-evolutionary history of wildlife with the disease causing agents.

Toxoplasma gondii is an apicomplexan parasite and the causative agent of human toxoplasmosis. It has a worldwide distribution and a broad range of intermediate hosts, but with only felids as definitive hosts (Tenter et al., 2000). Rodents play a particularly important role as intermediate hosts, because they are a prey for cats (Tenter et al., 2000). Furthermore, vertical transmission in rodents seems to contribute to the maintenance of Toxoplasma in areas with low cat density (Hide et al., 2009; Thomasson et al., 2011).

In most host species, infections with $T$. gondii are asymptomatic (Yarovinsky et al. 2008). However, in mice T. gondii appears to be more virulent, with a high mortality rate during the acute phase of infection (Zenner et al., 1998). Additionally, several studies have documented an alteration of behavior in chronically infected hosts (Webster and McConkey, 2010). Studies in laboratory mice, for example, have shown an impaired learning capacity (Hodkova et al., 2007; Webster, 2007), enhanced activity patterns (Hodkova et al., 2007; but see Hrdá et al., 2000) , and, most importantly, a reduction in the natural fear towards cat odour (Vyas et al., 2007; Xiao et al., 2012; but see Worth et al., 2013) in T. gondii infected rodents. The latter is likely to increase the host's predation risk in the wild. Given these negative fitness consequences of infection, we would expect rodents to evolve potent resistance mechanisms that prevent or control $T$. gondii infections. 
Pattern-recognition receptors (PRRs) belong to the innate branch of the vertebrate immune system and play an important role in the first line of defence against invading parasites (Akira et al., 2006). One important group of PRRs is the Toll-like receptor (TLR) family, which has diversified into several different TLRs in vertebrates, each recognizing specific pathogen structures (Roach et al., 2005). Studies have found a pronounced susceptibility to $T$. gondii in laboratory mice lacking the TLR adaptor protein MyD88, suggesting an involvement of TLRs in T. gondii defence (Scanga et al., 2002). Subsequent knock-out studies revealed that it is in particular TLR11, which plays an important role in T. gondii resistance. TLR11deficient mice are highly susceptible to Toxoplasma compared to wild-type mice (reviewed in Pifer and Yarovinsky, 2011; Yarovinsky, 2014). Moreover, it was found that the recently characterised receptor TLR12 also influences resistance to $T$. gondii in laboratory mice (Koblansky et al., 2013), either on its own (Koblansky et al., 2013) or by forming heterodimers with TLR11 (Andrade et al., 2013; Raetz et al., 2013). Indeed, mortality rates of TLR12-deficient mice even exceeded those of TLR11deficient mice during the acute phase of $T$. gondii infection (Koblansky et al., 2013). The ligand recognised by TLR11 and TLR12 is profilin (Yarovinsky et al., 2005; Kucera et al., 2010), which plays an important role in the motility, host cell invasion, and virulence of Toxoplasma (Plattner et al., 2008). Interestingly, both TLR11 and $T L R 12$ are expressed exclusively in rodents, and whereas $T L R 11$ exists as a pseudogene in humans, TLR12 is completely absent in the human genome (Roach et al., 2005). Given the important role of TLR11 and TLR12 in Toxoplasma recognition, we would predict polymorphisms at TLR11 and / or TLR12 ligand-binding sites to affect Toxoplasma susceptibility in the wild.

Previous studies in humans and domestic animals have found that $T L R$ polymorphisms affect susceptibility to a wide range of parasites and pathogens (e.g. 
Brightbill et al., 1999; Texereau et al., 2005; Garantziotis et al., 2008). Yet, very few studies have tested how naturally occurring polymorphisms at TLRs influence disease susceptibility in wildlife (but see e.g. Jackson et al., 2009; Turner et al., 2011; Tschirren et al., 2013). Here we quantified TLR11 and TLR12 genetic diversity and tested for associations between TLR polymorphisms and T. gondii infection in a natural population of wood mice (Apodemus sylvaticus).

\section{Material and Methods}

\subsection{Sample collection and detection of Toxoplasma gondii infection} Wood mice (Apodemus sylvaticus) are one of the main intermediate hosts of $T$. gondii in Europe and infection prevalence can reach high levels within populations (Thomasson et al., 2011). For this study, wood mice were trapped using Longworth small mammal traps at four sites (Tarn Wood $54^{\circ} 06^{\prime} 03.3^{\prime \prime} \mathrm{N}, 002^{\circ} 09^{\prime} 44.9^{\prime \prime} \mathrm{W}$, Spiggot Hill $54^{\circ} 05^{\prime} 72.9^{\prime \prime} \mathrm{N}, 002^{\circ} 10^{\prime} 43.1^{\prime \prime} \mathrm{W}$; Ha Mire Plantation $54^{\circ} 05^{\prime} 64.5^{\prime \prime} \mathrm{N}, 002^{\circ} 09^{\prime} 53.7^{\prime \prime} \mathrm{W}$ and Tarn Fen $54^{\circ} 06^{\prime} 00.0^{\prime \prime} \mathrm{N}, 002^{\circ} 10^{\prime} 43.4^{\prime \prime} \mathrm{W}$ ) within the boundaries of the Malham Tarn Nature Reserve in North Yorkshire, UK between October 2009 and October 2011 under a permit granted from the National Trust (see Boyce et al., 2012; Boyce et al., 2013 for details). The majority of mice were caught during the summer and autumn. Animals were euthanized, their body mass and body length (measured from nose to anus using a measuring board) was measured and they were dissected. The body mass of four individuals was not available. We calculated the scaled mass index as a measure of body condition (Peig \& Green, 2009). DNA was extracted from brain tissue using a phenol/chloroform protocol and the presence of $T$. gondii was detected by PCR amplification of the Surface Antigen Gene 1 (SAG1) as described in Thomasson et al. (2011). Infection was confirmed using a further panel of Toxoplasma-specific PCR diagnostic genes - SAG2, SAG3 and GRA6 (Bajnok et al., 
submitted). Ethical approval for this work was given by the College of Science and Technology Research Ethics Panel, University of Salford (Reference: CST 12/36).

\subsection{TLR11 and TLR12 genotyping}

TLR11 and TLR12 sites involved in pathogen recognition, so called leucine-rich repeat (LRR) motives, were predicted using the TollML database (Gong et al., 2010). A 979 bp long fragment of $T L R 11$ and a 862 bp long fragment of $T L R 12$, containing most of these LRR regions, was sequenced in 120 wood mice. Primers (TLR11ASF: 5'-CAG GGC ATG GTT CCT ACT CT-3'; TLR11ASR: 5'-TCT TGG GAC CCT GAA GTT GT-3' and TLR12ASF: 5'-CCT GAT GCC TTY RGT GAC CT-3'; TLR12ASR: 5'GCC GYT TAT RGT CAA GGT CT-3') were designed based on the house mouse (GenBank accession numbers NM_205819.3 and AY510705.1) and rat (GeneBank accession numbers NM_001144779.2 and NM_001108682.1) TLR11 and TLR12 sequences using the program Primer3 (Rozen \& Skaletsky 2000). Clean wood mouse sequences were obtained using these primers and a NCBI GenBank Blast search confirmed the amplification of $T L R 11$ and $T L R 12$, respectively. Polymerase chain reactions (PCR) were carried out on a GeneAmp PCR System 9700 thermocycler (Applied Biosystems). Amplifications were performed in a total volume of $10 \mu$ l containing $0.2 \mu$ l JumpStart Taq DNA Polymerase (Sigma-Aldrich), $300 \mathrm{nM}$ of each primer and $1 \mu$ I DNA. The PCR protocol consisted of an initial denaturation step at $94^{\circ} \mathrm{C}$ for $1 \mathrm{~min}$, followed by 35 cycles of denaturation at $94^{\circ} \mathrm{C}$ for $30 \mathrm{sec}$, annealing at $57^{\circ} \mathrm{C}$ for $30 \mathrm{sec}$, and extension at $72^{\circ} \mathrm{C}$ for $90 \mathrm{sec}$, with a final elongation step at $72^{\circ} \mathrm{C}$ for $10 \mathrm{~min}$. PCR products were purified and sequenced in both directions on an ABI Prism 3730 capillary sequencer (Applied Biosystems) using Big Dye terminator version 3.1 chemistry (Applied Biosystems). All TLR11 and TLR12 raw sequences were trimmed, processed and aligned in Geneious 5.6.5 (Drummond et al., 2009). Polymorphisms were detected by eye and haplotypes were 
reconstructed in the program PHASE 2.1 (Stephens et al., 2001) using default settings. TLR11 (accession numbers: KJ612408- KJ612411) and TLR12 (accession numbers: KJ612412 - KJ612420) haplotypes were submitted to GenBank.

\subsection{Statistical analyses}

The genealogy of TLR11 and TLR12 haplotypes was inferred with the program TCS (Clement et al., 2000), taking both synonymous and nonsynonymous mutation into account.

We tested if $T$. gondii infection was associated with $T L R 11$ and / or TLR12 genotypes (i.e. haplotype combinations), and if infection status differed between individuals that were TLR11 or TLR12 homozygous (twice the same haplotype) vs. heterozygous (two different haplotypes) using generalized linear models with a binomial error structure. We tested if epistatic interactions between TLR11 and TLR12 influenced infection status by fitting the interaction term between $T L R 11$ and $T L R 12$ genotypes in the model. Furthermore, we tested if $T$. gondii infection status is associated with certain TLR11 or TLR12 haplotypes, again using generalized linear models with a binomial error structure. Sex, body condition and sampling location were included as factors in the analyses to account for potential sex-specific or condition-related differences in infection patterns or potential differences in T. gondii prevalence among sampling locations. Genotypes and haplotypes that occurred at frequencies < $5 \%$ were pooled in a 'rare' category for the analyses. The significance of the different variables was determined by comparing two nested models, one with and one without the factor of interest, using likelihood-ratio tests. Statistical analyses were performed in R 2.14.2 (R Development Core Team, 2011). 


\section{Results}

We detected six TLR11 haplotypes in the studied wood mouse population, of which four differed at the amino acid level. TLR11 haplotypes 1 and 2 occurred at high frequencies (TLR11 $1_{H 1}: 31.9 \%$ and $\left.T L R 11_{H 2}: 65.5 \%\right)$, whereas haplotypes $T L R 11_{H 3}$ and $T L R 11_{\mathrm{H} 4}$ were found in only five and one individual, respectively (Fig. 1). For TLR12, we observed 13 haplotypes of which nine differed at the amino acid level. $T L R 12_{H 1}$ was the most common haplotype (frequency: $77.9 \%$ ). Haplotypes $T L R 12_{H 2}$ and $T L R 12_{H 6}$ occurred at frequencies of $5.8 \%$ and $10.8 \%$, respectively. All other haplotypes were rare (frequency: $0.4-1.7 \%$, Fig. 1). The reconstructed genealogies of TLR11 and TLR12 haplotypes are shown in Figure 1.

Toxoplasma gondii was detected in $36 \%$ of the analysed wood mice $(\mathrm{N}=120)$. Infected animals tended to be lighter $\left(\chi^{2}=3.263, D F=1, P=0.071\right)$ and in worse condition $\left(\chi^{2}=3.071, D F=1, P=0.080\right)$, but there was no association between body size and infection status $\left(\chi^{2}=0.083, D F=1, P=0.773\right)$. There was a tendency for a higher infection rate in females $\left(\chi^{2}=2.950, D F=1, P=0.089\right)$.

Toxoplasma infection status was not significantly associated with $\operatorname{TLR} 11\left(\chi^{2}=\right.$ 3.541, $D F=3, P=0.315 ;$ Table 1$)$ or $T L R 12$ genotype $\left(\chi^{2}=4.264, D F=3, P=\right.$ 0.234; Table 1), and there was no significant interaction effect between TLR11 and TLR12 genotype on $T$. gondii infection $\left(\chi^{2}=5.028, D F=8, P=0.755\right)$. Furthermore, there was no significant association between $T L R 11$ (all $P>0.283$ ) or $T L R 12$ haplotypes (all $P>0.090$ ) and Toxoplasma infection. Finally, there was no relationship between $T L R 11\left(\chi^{2}=0.330, D F=1, P=0.566\right)$ or $T L R 12$ heterozygosity $\left(\chi^{2}=0.964, D F=1, P=0.326\right)$ and $T$. gondii infection status. 


\section{Discussion}

Laboratory-based studies demonstrated that TLR11 and TLR12, two innate immune receptors only expressed in rodents, play a key role in the recognition and initiation of immune responses against $T$. gondii in laboratory mice (Yarovinsky, 2014). Here we transferred these findings into an ecologically meaningful context to test, firstly if TLR11 and / or TLR12 are polymorphic, and secondly, if TLR11 and / or TLR12 variants are associated with T. gondii infection in Apodemus sylvaticus, one of the main intermediate hosts of $T$. gondii in Europe.

We observed an intermediate level of genetic diversity at $T L R 11$, with four amino acid haplotypes. Two of these haplotypes were rare, whereas the other two were both common and occurred at intermediate frequencies. For TLR12, we found that gene diversity was higher with nine haplotypes that differed at the amino acid level, but haplotype frequencies were more skewed with one haplotype being very common. Whereas this is the first study to quantify genetic diversity at $T L R 11$ or $T L R 12$ in a natural rodent population, studies on the diversity at other TLRs in wildlife are starting to accumulate. TLR2 for example is highly polymorphic in bank voles (Myodes glareolus), but shows low levels of diversity in yellow-necked mice (Apodemus flavicollis) (Tschirren et al., 2011; Tschirren et al., 2012). Furthermore, in a bottlenecked population of New Zealand robin (Petroica australis rakiura), seven out of nine analysed TLRs were polymorphic, with two to five amino acid variants each (Grueber et al., 2012). This relatively high genetic diversity observed in wildlife is in agreement with human studies (Mukherjee et al., 2009; Wlasiuk and Nachman, 2010), and shows that there is the potential for parasite-mediated selection to act on TLRs. 
Although we observed variation at $T L R 11$ and $T L R 12$ on which $T$. gondii-mediated selection could act on, we found no evidence that TLR11 or TLR12 genotypes or haplotypes were significantly associated with $T$. gondii infection. Interestingly, $T$. gondii prevalence was almost twice as high among animals with a rare genotype compared to animals with a common genotype. However, given the small number of animals with a rare genotype, we can currently only speculate if this difference is due to chance, or if rare $T L R 11$ and $T L R 12$ genotypes are associated with a higher $T$. gondii susceptibility, and are rare because they have a selective disadvantage. There was no evidence for epistatic interactions between TLR11 and TLR12 genotypes on infection status. Also, we found no indication for a TLR11 or TLR12 heterozygote advantage. Although TLR11 and TLR12 play an important role in the recognition and control of $T$. gondii in laboratory mice (Pifer and Yarovinsky, 2011; Koblansky et al., 2013), and both are expressed exclusively in rodents (Roach et al., 2005), TLR11 and TLR12 genetic polymorphisms thus appear to play a minor role in mediating variation in $T$. gondii susceptibility in our study population.

This finding is in contrast to a recent study on bank voles, which demonstrated a strong association between TLR2 haplotypes and Borrelia afzelii infection (Tschirren et al., 2013). As for TLR11 / TLR12 and T. gondii, this study was based on the finding that $T L R 2$ is essential for the recognition and initiation of immune responses against Borrelia, and that $T L R 2$-deficient mice show a markedly increased susceptibility to Borrelia in the laboratory (Alexopoulou et al., 2002; Wooten et al., 2002).

The lack of an association between TLR11 and / or TLR12 variants and T. gondii infection could have a number of reasons. First, we considered only infection status (i.e. qualitative resistance), but not infection intensity (i.e. quantitative resistance) in our study. Thus, we cannot exclude the possibility that TLR11 and / or TLR12 polymorphisms influence quantitative resistance against $T$. gondii. Second, 
the severity of behavioural manipulation by $T$. gondii appears to depend on which brain regions are affected by the parasite (Haroon et al., 2012; but see McConkey et al., 2013). A more detailed analysis of infection patterns might thus increase the power to detect potential associations with TLR variants. Third, T. gondii strains differ substantially in virulence (Grigg et al., 2001; Saeij et al., 2005), at least under laboratory conditions, and we have no information on how severe the fitness consequences of $T$. gondii infection are in our study populations. If fitness consequences are comparably mild, we would not expect $T$. gondii to exert strong selection on its host's immune system. Fourth, experimental evidence that T. gondii susceptibility is TLR11- and TLR12-dependent comes from studies on laboratory mice. If the function of TLRs differs across rodent genera, this might explain the lack of an association between TLR11 and TLR12 variation and $T$. gondii infection in our study. However, given the high level of structural and functional conservation of TLRs in vertebrates (Roach et al., 2005), this scenario seems unlikely. Finally, a potential association between TLR variants and T. gondii infection could be masked by third factors that could not be controlled for in this field study. Importantly, however, and despite all these factors that may reduce statistical power, the lack of an association between T. gondii infection and TLR11 / 12 variants illustrates that Toxoplasmamediated selection on these immune receptors is weak at best in our study population.

In conclusion, we show that although previous studies have shown that TLR11 and TLR12 are essential for the recognition and initiation of immune responses against $T$. gondii in laboratory mice, TLR11 and TLR12 polymorphisms do not appear to mediate variation in Toxoplasma susceptibility in wild-living wood mice. Our results indicate that pathways essential for host defence identified in a laboratory 
setting are not necessarily the main targets of parasite-mediated selection in natural host-parasite systems.

\section{Acknowledgements}

The study was financially supported by the University of Zurich Research Priority

Program 'Evolution in Action: From Genomes to Ecosystems' (to BT), the University of Salford and the British Society of Parasitology (to GH). BT holds a Swiss National Science Foundation Assistant Professorship (PP00P3_128386). ZRL's laboratory is supported by the National Basic Research Program of China (973 Program; \#2010CB530000). We would like to thank the National Trust, UK, and the Field Studies Council, UK, and especially Adrian Pickles, for permitting us to sample and to use their facilities.

\section{Declaration of interest}

Authors have no declarations of interest to report. 
Figure legend

Figure 1: Haplotype network

Haplotype genealogy of A) TLR11 and B) TLR12 based on 120 individuals.

Displayed are all haplotypes. The circle sizes reflect the number of haplotype copies observed in the population. The same numbers (e.g. 1a, 1b) identify haplotypes that are identical at the amino acid level. Each line indicates a change at one nucleotide.
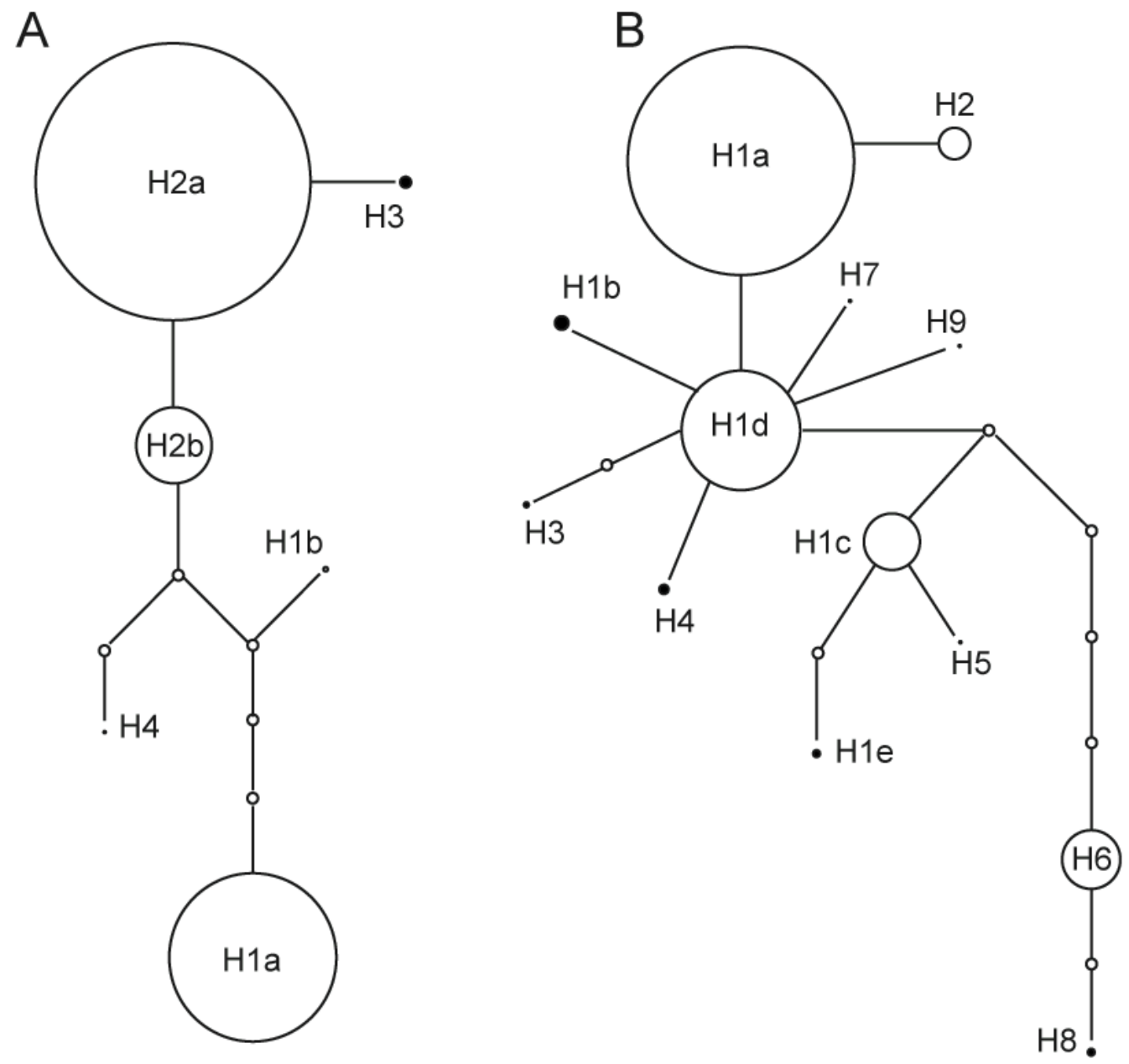
Table 1: Toxoplasma gondii infection across TLR11 and TLR12 genotypes

TLR11 and TLR12 genotypes (synonymous haplotypes were combined), number of individuals $(\mathrm{N})$, and percentage of $T$. gondii-infected individuals per genotype.

Genotypes with a frequency $<5 \%$ were combined into the category 'rare'.

\begin{tabular}{lcc}
\hline TLR11 & $\mathbf{N}$ & Infected [\%] \\
\hline H1/H1 & 18 & 38.9 \\
H1/H2 & 38 & 31.6 \\
H2/H2 & 58 & 34.5 \\
rare & 6 & 66.7 \\
& & \\
\hline TLR12 & $\mathbf{N}$ & Infected [\%] \\
\hline H1/H1 & 72 & 33.3 \\
H1/H2 & 13 & 30.8 \\
H1/H6 & 22 & 31.8 \\
rare & 13 & 61.5
\end{tabular}




\section{References}

Abolins, S.R., Pocock, M.J.O., Hafalla, J.C.R., Riley, E.M., Viney, M.E., 2011.

Measures of immune function of wild mice, Mus musculus. Mol. Ecol. 20, 881-892.

Akira, S., Uematsu, S., Takeuchi, O., 2006. Pathogen recognition and innate immunity. Cell 124, 783-801.

Alexopoulou, L., Thomas, V., Schnare, M., Lobet, Y., Anguita, J., Schoen, R.T., Medzhitov, R., Fikrig, E., Flavell, R.A., 2002. Hyporesponsiveness to vaccination with Borrelia burgdorferi OspA in humans and in TLR1- and TLR2-deficient mice. Nature Med. 8, 878-884.

Andrade, W.A., Souza, M.D., Ramos-Martinez, E., Nagpal, K., Dutra, M.S., Melo, M.B., Bartholomeu, D.C., Ghosh, S., Golenbock, D.T., Gazzinelli, R.T., 2013. Combined action of nucleic acid-sensing Toll-like receptors and TLR11/TLR12 heterodimers imparts resistance to Toxoplasma gondii in mice. Cell Host Microbe 13, 42-53.

Apanius, V., Penn, D., Slev, P.R., Ruff, L.R., Potts, W.K., 1997. The nature of selection on the major histocompatibility complex. Crit. Rev. Immunol. 17, 179-224. Bajnok, J., Boyce, K., Rogan, M.T., Craig, P.S., Lun, Z.R., Hide, G., submitted. Prevalence of Toxoplasma gondii in localised populations of Apodemus sylvaticus is linked to population genotype not to population location. Parasitology. Boyce, K., Hide, G., Craig, P., Reynolds, C., Hussain, M., Bodell, A., Bradshaw, H., Pickles, A., Rogan, M., 2013. A molecular and ecological analysis of the trematode Plagiorchis elegans in the wood mouse Apodemus sylvaticus from a periaquatic ecosystem in the UK. J. Helminthol. 19, 1-11.

Boyce, K., Hide, G., Craig, P.S., Harris, P.D., Reynolds, C., Pickles, A., Rogan, M.T., 2012. Identification of a new species of digenean Notocotylus malhamensis $n$. sp 
(Digenea: Notocotylidae) from the bank vole (Myodes glareolus) and the field vole (Microtus agrestis). Parasitology 139, 1630-1639.

Boysen, P., Eide, D.M., Storset, A.K., 2011. Natural killer cells in free-living Mus musculus have a primed phenotype. Mol. Ecol. 20, 5103-5110.

Brightbill, H.D., Libraty, D.H., Krutzik, S.R., Yang, R.B., Belisle, J.T., Bleharski, J.R., Maitland, M., Norgard, M.V., Plevy, S.E., Smale, S.T., Brennan, P.J., Bloom, B.R., Godowski, P.J., Modlin, R.L., 1999. Host defense mechanisms triggered by microbial lipoproteins through Toll-like receptors. Science 285, 732-736.

Clement, M., Posada, D., Crandall, K.a., 2000. TCS: a computer program to estimate gene genealogies. Mol. Ecol. 9, 1657-1659.

Drummond, A.J., Ashton, B., Cheung, M., Heled, J., Kearse, M., Moir, R., StonesHavas, S., Thierer, T., Wilson, A., 2009. Geneious v4.6. Available at

\section{http://www.geneious.com.}

Fumagalli, M., Pozzoli, U., Cagliani, R., Comi, G.P., Riva, S., Clerici, M., Bresolin, N., Sironi, M., 2009. Parasites represent a major selective force for interleukin genes and shape the genetic predisposition to autoimmune conditions. J. Exp. Med. 206, 13951408.

Garantziotis, S., Hollingsworth, J.W., Zaas, A.K., Schwartz, D.A., 2008. The effect of Toll-like receptors and Toll-like receptor genetics in human disease. Ann. Rev. Med. 59, 343-359.

Gong, J., Wei, T., Zhang, N., Jamitzky, F., Heckl, W.M., Rössle, S.C., Stark, R.W., 2010. TollML: a database of Toll-like receptor structural motifs. J. Mol. Mod. 16, $1283-1289$

Grigg, M.E., Bonnefoy, S., Hehl, A.B., Suzuki, Y., Boothroyd, J.C., 2001. Success and virulence in Toxoplasma as the result of sexual recombination between two distinct ancestries. Science 294, 161-165. 
Grueber, C.E., Wallis, G.P., King, T.M., Jamieson, I.G., 2012. Variation at innate immunity Toll-like receptor genes in a bottlenecked population of a New Zealand robin. PLoS One 7(9), e45011. doi:10.1371/journal.pone.0045011.

Haroon, F.H.n., Ulrike, Angenstein, F., Goldschmidt, J., Kreutzmann, P., Lison, H., Fischer, K.D., Scheich, H., Wetzel, W., Schlüter, D., Budinger, E., 2012. Toxoplasma gondii actively inhibits neuronal function in chronically infected mice. PLoS One 7, e35516.

Hedrick, P.W., 2002. Pathogen resistance and genetic variation at MHC loci. Evolution 56, 1902-1908.

Hide, G., Morley, E.K., Hughes, J.M., Gerwash, O., Elmahaishi, M.S., Elmahaishi, K.H., Thomasson, D., Wright, E.A., Williams, R.H., Murphy, R.G., Smith, J.E., 2009. Evidence for high levels of vertical transmission in Toxoplasma gondii. Parasitology $136,1877-1885$

Hill, A.V.S., 2001. The genomics and genetics of human infectious disease susceptibility. Annu. Rev. Genomics Hum. Genet. 2, 373-400.

Hodkova, H., Kodym, P., Flegr, J., 2007. Poorer results of mice with latent toxoplasmosis in learning tests: impaired learning processes or the novelty discrimination mechanism? Parasitology 134, 1329-1337.

Hrdá, S., Votýpka, J., Kodym, P., Flegr, J., 2000. Transient nature of Toxoplasma gondii-induced behavioral changes in mice. J. Parasitol. 86, 657-663.

Jackson, J.A., Friberg, I.M., Bolch, L., Lowe, A., Ralli, C., Harris, P.D., Behnke, J.M., Bradley, J.E., 2009. Immunomodulatory parasites and toll-like receptor-mediated tumour necrosis factor alpha responsiveness in wild mammals. BMC Biology 7, doi:10.1186/1741-7007-7-16.

Kaslow, R.A., McNicholl, J., Hill, A.V.S., 2008. Genetic Susceptibility to Infectious Diseases. Oxford University Press, New York. 
Koblansky, A.A., Jankovic, D., Oh, H., Hieny, S., Sungnak, W., Mathur, R., Hayden, M.S., Akira, S., Sher, A., Ghosh, S., 2013. Recognition of profilin by Toll-like receptor 12 is critical for host resistance to Toxoplasma gondii. Immunity $38,119-130$.

Kucera, K., Koblansky, A.A., Saunders, L.P., Frederick, K.B., De La Cruz, E.M., Ghosh, S., Modis, Y., 2010. Structure-based analysis of Toxoplasma gondii profilin: a parasite-specific motif is required for recognition by Toll-like receptor 11 . J. Mol. Biol. 403, 616-629.

Li, C., Corraliza, I., Langhorne, J., 1999. A defect in interleukin-10 leads to enhanced malarial disease in Plasmodium chabaudi chabaudi infection in mice. Infect. Immun. $67,4435-4442$.

Maizels, R.M., Nussey, D.H., 2013. Into the wild: digging at immunology's evolutionary roots. Nat. Immunol. 14, 879-883.

McConkey, G.A., Martin, H.L., Bristow, G.C., Webster, J.P., 2013. Toxoplasma gondii infection and behaviour: location, location, location? J. Exp. Biol. 216, 113-119. Mukherjee, S., Sarkar-Roy, N., Wagener, D.K., Majumder, P.P., 2009. Signatures of natural selection are not uniform across genes of innate immune system, but purifying selection is the dominant signature. Proc. Natl. Acad. Sci. USA 106, 70737078.

Pedersen, A.B., Babayan, S.A., 2011. Wild immunology. Mol. Ecol. 20, 872-880. Pifer, R., Yarovinsky, F., 2011. Innate responses to Toxoplasma gondii in mice and humans. Trends Parasitol. 27, 388-393.

Peig, J., Green, A.J., 2009. New perspectives for estimating body condition from mass/length data: the scaled mass index as an alternative method. Oikos 118, 18831891. 
Plattner, F., Yarovinsky, F., Romero, S., Didry, D., Carlier, M.F., Sher, A., SoldatiFavre, D., 2008. Toxoplasma profilin is essential for host cell invasion and TLR11dependent induction of an interleukin-12 response. Cell Host Microbe 3, 77-87. R Development Core Team, 2011. R: A language and environment for statistical computing. http://www.R-project.org.

Raetz, M., Kibardin, A., Sturge, C.R., Pifer, R., Li, H.Y., Burstein, E., Ozato, K., Larin, S., Yarovinsky, F., 2013. Cooperation of TLR12 and TLR11 in the IRF8-dependent IL-12 response to Toxoplasma gondii profilin. J. Immunol. 191, 4818-4827.

Roach, J.C., Glusman, G., Rowen, L., Kaur, A., Purcell, M.K., Smith, K.D., Hood, L.E., Aderem, A., 2005. The evolution of vertebrate Toll-like receptors. Proc. Natl. Acad. Sci. USA 102, 9577-9582.

Sackton, T.B., Lazzaro, B.P., Schlenke, T.A., Evans, J.D., Hultmark, D., Clark, A.G., 2007. Dynamic evolution of the innate immune system in Drosophila. Nat. Genet. 39, 1461-1468.

Saeij, J.P.J., Boyle, J.P., Boothroyd, J.C., 2005. Differences among the three major strains of Toxoplasma gondii and their specific interactions with the infected host. Trends Parasitol. 21, 476-481.

Scanga, C.A., Aliberti, J., Jankovic, D., Tilloy, F., Bennouna, S., Denkers, E.Y., Medzhitov, R., Sher, A., 2002. Cutting edge: MyD88 is required for resistance to Toxoplasma gondii infection and regulates parasite-induced IL-12 production by dendritic cells. J. Immunol. 168, 5997-6001.

Stephens, M., Smith, N.J., Donnelly, P., 2001. A new statistical method for haplotype reconstruction from population data. Am. J. Hum. Genet. 68, 978-989.

Tenter, A.M., Heckeroth, A.R., Weiss, L.M., 2000. Toxoplasma gondii: from animals to humans. Int. J. Parasitol. 30, 1217-1258. 
Texereau, J., Chiche, J.D., Taylor, W., Choukroun, G., Comba, B., Mira, J.P., 2005. The importance of Toll-like receptor 2 polymorphisms in severe infections. Clin. Infect. Dis. 41, S408-S415.

Thomasson, D., Wright, E.A., Hughes, J.M., Dodd, N.S., Cox, A.P., Boyce, K., Gerwash, O., Abushahma, M., Lun, Z.R., Murphy, R.G., Rogan, M.T., Hide, G., 2011. Prevalence and co-infection of Toxoplasma gondii and Neospora caninum in Apodemus sylvaticus in an area relatively free of cats. Parasitology 138, 1117-1123. Tiffin, P., Moeller, D.A., 2006. Molecular evolution of plant immune system genes. Trends Genet. 22, 662-670.

Tschirren, B., Andersson, A., Scherman, K., Westerdahl, H., Mittl, P., Raberg, L., 2013. Polymorphisms at the innate immune receptor TLR2 are associated with Borrelia infection in a wild rodent population. Proc. R. Soc. B 280, 10.1098/rspb.2013.0364.

Tschirren, B., Andersson, M., Scherman, K., Westerdahl, H., Råberg, L., 2012.

Contrasting patterns of diversity and population differentiation at the innate immunity gene Toll-like receptor 2 (TLR2) across populations of two sympatric rodent species. Evolution 66, 720-731.

Tschirren, B., Råberg, L., Westerdahl, H., 2011. Signatures of selection acting on the innate immunity gene Toll-like receptor 2 (TLR2) during the evolutionary history of rodents. J. Evol. Biol. 24, 1232-1240.

Turner, A.K., Begon, M., Jackson, J.A., Bradley, J.E., Paterson, S., 2011. Genetic diversity in cytokines associated with immune variation and resistance to multiple pathogens in a natural rodent population. PLoS Genetics 7, e1002343. doi:1002310.1001371/journal.pgen.1002343. 
Turner, A.K., Begon, M., Jackson, J.a., Paterson, S., 2012. Evidence for selection at cytokine loci in a natural population of field voles (Microtus agrestis). Mol. Ecol. 21, 1632-1646.

Turner, A.K., Paterson, S., 2013. Wild rodents as a model to discover genes and pathways underlying natural variation in infectious disease susceptibility. Parasite Immunol. 35, 386-395.

Vyas, A., Kim, S.-K., Giacomini, N., Boothroyd, J.C., Sapolsky, R.M., 2007.

Behavioral changes induced by Toxoplasma infection of rodents are highly specific to aversion of cat odors. Proc. Natl. Acad. Sci. USA 104, 6442-6447.

Webster, J.P., 2007. The effect of Toxoplasma gondii on animal behavior: playing cat and mouse. Schizophr. Bull. 33, 752-756.

Webster, J.P., McConkey, G.A., 2010. Toxoplasma gondii-altered host behaviour: clues as to mechanism of action. Folia Parasitol. 57, 95-104.

Wlasiuk, G., Nachman, M.W., 2010. Adaptation and constraint at Toll-like receptors in primates. Mol. Biol. Evol. 27, 2172-2186.

Woolhouse, M.E.J., Webster, J.P., Domingo, E., Charlesworth, B., Levin, B.R., 2002. Biological and biomedical implications of the co-evolution of pathogens and their hosts. Nat. Genet. 32, 569-577.

Wooten, R.M., Ma, Y., Yoder, R.A., Brown, J.P., Weis, J.H., Zachary, J.F., Kirschning, C.J., Weis, J.J., 2002. Toll-like receptor 2 is required for innate, but not acquired, host defense to Borrelia burgdorferi. J. Immunol. 168, 348-355.

Worth, A.R., Lymbery, A.J., Thompson, R.C.A., 2013. Adaptive host manipulation by Toxoplasma gondii: fact or fiction? Trends Parasitol. 29, 150-155.

Xiao, J., Kannan, G., Jones-Brando, L., Brannock, C., Krasnova, I.N., Cadet, J.L., Pletnikov, M., Yolken, R.H., 2012. Sex-specific changes in gene expression and behavior induced by chronic Toxoplasma infection in mice. Neuroscience 206, 39-48. 
Yarovinsky, F., 2014. Innate immunity to Toxoplasma gondii infection. Nat. Rev.

Immunol. 14, 109-121.

Yarovinsky, F., Zhang, D.K., Andersen, J.F., Bannenberg, G.L., Serhan, C.N.,

Hayden, M.S., Hieny, S., Sutterwala, F.S., Flavell, R.A., Ghosh, S., Sher, A., 2005.

TLR11 activation of dendritic cells by a protozoan profilin-like protein. Science 308, 1626-1629.

Zenner, L., Darcy, F., Capron, A., Cesbron-Delauw, M.F., 1998. Toxoplasma gondii: Kinetics of the dissemination in the host tissues during the acute phase of infection of mice and rats. Exp. Parasitol. 90, 86-94. 